\title{
Dynamic stock market integration driven by the European Monetary Union: An empirical analysis
}

Suk Joong Kim

Fariborz Moshirian*

Eliza Wu

School of Banking and Finance, University of New South Wales, Sydney, NSW 2052, Australia.

\begin{abstract}
We examine the influence of the European Monetary Union (EMU) on the dynamic process of stock market integration over the period 2 January 1989 - 29 May 2003 using a bivariate EGARCH framework with time-varying conditional correlations. We find that there has been a clear regime shift in European stock market integration with the introduction of the EMU. The EMU has been necessary for stock market integration as unidirectional causality was found. Linear systems regression analysis show that the increase in both regional and global stock market integration over this period was significantly driven in part, by macroeconomic convergence associated with the introduction of the EMU and financial development levels.
\end{abstract}

JEL Classification: C32; E44; F3; G14; G15

Keywords: Euro, currency unions, stock market linkages, time-varying financial market integration.

*Corresponding author. Tel.: +61-2-93855859; Fax: +61-2-93856730; Email address: f.moshirian@unsw.edu.au. 


\section{Introduction}

There is no doubt that capital market integration was one motivation for the European Economic and Monetary Union (EMU). The euro was introduced as the single currency for the EMU on January $1^{\text {st }}$, 1999 following an economic, monetary and financial convergence process that had spanned over two decades from the initial creation of the European Monetary System (EMS). The political creation of the euro presents a learning model for understanding the financial effects of currency unions given that the euro was introduced without a single euro area financial market. The concept of financial market integration is central to the international finance literature. It is well accepted in the theoretical literature that integration of financial markets is fundamentally linked to economic growth through risk sharing benefits, improvements in allocational efficiency and reductions in macroeconomic volatility (see Pagano, 1993, Prasad et al., 2003, Baele et al., 2004). Given the significant potential benefits from financial market integration, this paper investigates the nature and the determinants of stock market integration with a view to evaluating the effectiveness of the EMU in its promotion.

First, we discuss how European stock market linkages and integration dynamics have evolved over the past fifteen years on both a regional and global scale in response to the economic convergence process associated with the formation of the EMU. Second, we address the causality issue between currency unions and financial market integration to improve our understanding on the sequencing of financial market integration. Finally, we identify the factors that determine these integration patterns in a new empirical context and assess whether they are consistent for both regional and global stock market integration. The research questions addressed in this paper have obvious implications for policy-makers in an increasingly interdependent global financial architecture and for investors’ asset allocation 
decisions ${ }^{1}$. There is a clear need to better understand how and why the EMU has affected stock markets because of their important role in facilitating financing and investment decisions.

In principle, it is reasonable for investors to view a single currency zone as a single area of financial opportunity. To a large extent, financial market integration is driven by market forces but constrained by regulatory barriers and the level of integration is not uniform across market segments nor across time. Hence, financial markets and investment returns should be driven to some time varying degree of convergence. ${ }^{2}$

Recent studies by Hardouvelis et al. (1999), Fratzscher (2002), Morana and Beltratti (2002), Yang et al. (2003) and Baele (2004) provide empirical evidence on the impact of the introduction of the euro on European stock markets. However, these studies remain incomplete and have the following shortfalls: i) They are confined to stock market changes up to 2001 and cover only selected EMU countries. Thus longer term, post-euro impacts on international stock markets from the European currency unification are not well documented nor understood. Convergence towards the weighted average of the twelve members of the EMU has never been fully assessed. It is not even clear to what extent the formation of the EMU has changed the integration process of European stock markets ${ }^{3}$. ii) These studies have merely associated the changes in European stock markets to various aspects of the currency union without addressing the fundamental causal relationship between the two. iii) European

\footnotetext{
${ }^{1}$ The covariance/correlation matrix of international stocks is a key determinant of asset allocation in investment portfolios. Modern portfolio theory asserts that international diversification of equity portfolios improves the risk-return tradeoff if there is a low correlation between national stock markets (Solnik, 1974).

${ }^{2}$ The time varying nature of financial market integration is well established in the literature. See Bekaert and Harvey (1995) and Longin and Solnik (1995).

${ }^{3}$ An assessment of Greece’s late entry and integration into the EMU since 2001 has never received academic attention despite the important implications for the next stage of EU enlargement to begin in May 2004.
} 
stock market integration has only ever been assessed on a country by country basis and rarely as a group or system of member states which are similar by nature of their common convergence towards the EMU. iv) Although these studies attempt to explain why European stock markets have changed with the introduction of the euro, their findings are conflicting especially with respect to the reduction in exchange rate risk. Fratzscher (2002) and Beale (2004) find a key role for exchange rate stability and economic convergence leading up to the euro’s launch, whilst Morana and Beltratti (2002) attributes changes in stock market volatility to the unification of interest rates and stabilization of macroeconomic fundamentals and not to the elimination of exchange rate risk and v) Seasonal effects have not been examined despite their presence in other international stock market studies (eg., Longin and Solnik, 1995, Karolyi and Stulz, 1996 and Carrieri et al., 2001).

To address these gaps and disparities in the existing literature and to contribute an updated analysis on the extent to which stock market integration has been driven by the EMU, in this study we construct a bivariate daily exponential generalized autoregressive conditional heteroscedasticity (EGARCH) model for individual and value-weighted regional stock index returns. We focus primarily on documenting and explaining the time varying conditional correlations between these time series during the lead up to the establishment of the European currency union and beyond. Our contributions to the literature are in: i) Providing more comprehensive evidence from all pre-enlargement EU15 members as well as Japan and the US on the evolution of stock market integration at the regional and global level over a longer post-euro period; ii) Illustrating a two step estimation methodology that is suitable for empirical research on financial market integration; iii) Providing quantitative estimates on national and regional linkages between international equity markets during the different phases of European stock market integration; iv) Addressing the causal relationship between the EMU and stock market integration and v) Using additional information captured in linear 
systems estimations to find the determinants of stock market integration, including seasonal effects.

Our main findings with the benefit of a longer post-euro sample period are: i) a clear regime shift in stock market comovements within the EU and deeper stock market linkages with the introduction of the euro; ii) a currency union is necessary for financial market integration as the EMU has caused stock market integration between member states and vis-àvis Japan and the US; iii) stock market integration is primarily a persistent and seasonal process where stock market development and existing levels of integration are vital; iv) the January effect is significant but contrary to Karolyi and Stulz's (1996) study on the comovements between Japanese and US stock market returns, we find little evidence for day of the week effects in comovements with stock markets in the EMU and v) whilst the EMU has fostered stock market integration, we find that the reduction in exchange rate volatility has only been important for the smaller member states with historically different economic structures and that economic convergence within the region has had differing impacts on the integration of European stock markets in our sample period.

The rest of the paper is organized in the following way. Section 2 provides a brief literature review. Section 3 offers discussions on the data and methodology as well as the findings on the nature of stock market integration over time. Section 4 examines the role of various determinants of the stock market integration process. Finally, concluding remarks are presented in Section 5.

\section{Literature review}

The true process of financial market integration is dynamic and difficult to measure, and a wide range of empirical methodologies have been used to analyze the issue. The most basic 
technique has been the use of unconditional cross-country correlations on equity prices and returns. However, the debate on the relative importance of industry and country-specific effects in explaining cross-country correlations and volatility is yet to be resolved. ${ }^{4}$ Later on, atheoretical vector autoregressions (VARs) were used by Eun and Shim (1989), King and Wadhwani (1990) and others. Higher frequency data led to the use of ARCH variants, with Hamao et al. (1990) examining linkages and spillovers using daily returns and Susmel and Engel (1994) using hourly data to analyze major stock markets in London, New York and Tokyo. However, it is now known that ARCH is less useful for the non-normal distributions exhibited by emerging market returns. Instead, semi-parametric ARCH (SPARCH) has been used by Bekeart and Harvey (1997) to capture the fat tails and skewness in emerging market returns.

On another front, both univariate and multivariate cointegration/error correction models have been used to model stock returns and prices for major and emerging markets. ${ }^{5}$ However, we argue that the long-run stable equilibrium relationships conjectured by these techniques are not suitable for modeling the dynamic process of stock market integration as it is incomplete and continues to exhibit strong variations over time. Furthermore, only the existence of an equilibrating process and not the driving forces behind the long-run equilibrium are investigated in standard cointegration analyses.

In the past decade, multiple classes of univariate and multivariate GARCH models have been the technique of choice for research into financial links across equity markets. This is due to the high degree of persistence in the conditional means and variances of asset prices at high frequency levels. It is also well accepted in the empirical finance literature that the

\footnotetext{
${ }^{4}$ See Forbes and Chinn (2003) for an exposition on the cross-country correlations in asset returns literature.

${ }^{5}$ See Chen et al. (2002) and Bessler and Yang (2003) for other empirical studies using the cointegration and/or vector error correction technique(s).
} 
volatility of rising and falling (especially during recessions and/or financial crises) financial markets differ and that negative shocks (bad news) have a greater impact than positive shocks (good news). ${ }^{6}$ Hence, variants of these models have been used to accommodate the possibilities of non-normalities and asymmetries in the variance of returns (Glosten et al., 1993, Bekaert and Harvey, 1997, and Fratzscher, 2002 among others). Closely related to these are the regime switching models with time varying transition probabilities for different regimes used in Bekaert and Harvey (1995, 1997), Hardouvelis et al. (1999), Morana and Beltratti (2002) and Baele (2004) among others.

To address variations in stock market integration over time, researchers have performed regressions on different sub-periods to gain insight into long-term changes in stock market integration dynamics (see Longin and Solnik, 1995 and Bodart and Reding, 1999). More recently, rolling and recursive windows and time varying coefficients generated by instrumental variables have also been employed in Fratzscher (2002).

In this study, we employ a bivariate EGARCH model with a joint student $t$ conditional density function for the residuals to explicitly account for positive and negative shocks and fat tails in the equity returns. We will show that this model is well suited for modeling the dynamics of stock market returns. Fratzscher (2002) and Baele (2004) measured stock market integration using time varying coefficients on return spillovers and regime switching volatility spillover intensities respectively. However, the orthogonality condition required for unbiased estimates (due to the three shock components modeled) may be difficult to ascertain. Instead we use time-variations in conditional correlations from the EGARCH model. ${ }^{7}$ This provides a

\footnotetext{
${ }^{6}$ See Nelson (1991) and Glosten et al. (1993).

${ }^{7}$ The concerns of Forbes and Rigobon (2002) with using correlation coefficients to measure stock market comovements in the closely related financial contagion literature is not relevant to our study as reductions in European stock market volatility have already been shown by Morana and Beltratti (2002). Hence, we are confident that our conditional correlations are not a by-product of increasing volatility in stock returns.
} 
more direct indication of interdependence between individual stock markets and the EMU. It is also not reliant on the classification of volatility states required by regime switching models.

\section{Documenting time varying stock market integration}

In this section we show the extent to which international stock markets have been integrated with the EMU over the past fifteen years. We first discuss the data used and their statistical properties before detailing the empirical model and its results.

\subsection{Stock market data}

The European Union (EU) provides a natural setting for analyzing the differential impacts on stock market interdependence from idiosyncratic developments between constituent members within a currency union. The empirical analysis is therefore conducted for a sample set of countries that fall into two distinct groups: 1) The twelve eurozone members that have adopted the euro as a common currency (Austria, Belgium, Finland, France, Germany, Greece, Ireland, Italy, Luxembourg, Netherlands, Portugal and Spain) ${ }^{8}$ and 2) The non-eurozone countries which include the three remaining EU states that opted to stay out of the EMU (Denmark, Sweden, the UK) and Japan and US (the world's other two major stock markets).

The national stock market (continuously compounding) returns examined in this study are measured as the log of changes in closing index levels from one trading day to the next

\footnotetext{
${ }^{8}$ Greece had failed to meet the economic (convergence) criteria required under the Stability and Growth Pact of 1998. Greece adopted the euro on $1^{\text {st }}$ January 2001.
} 
such that, $R_{i t}=\ln \left(P_{t} / P_{t-1}\right) \times 100$ for stock market $i$ on day $t$. The national share market indices used are from Datastream International and are in local currency units with daily frequency from 2 January 1989 to 29 May 2003 (amounting to 3760 usable observations). ${ }^{9}$ Local currency returns are needed in our study to explicitly investigate the impact of changes in exchange rate risk induced by the introduction of the euro. Also, daily frequency is important given that comovements in the equity return generating process may often change rapidly. The stock market returns for the entire eurozone is calculated as the (market) valueweighted average return of the twelve EMU markets that have already adopted the euro. However, the value-weighted eurozone returns used for bivariate estimations with each individual EMU market $i$, is exclusive of that market itself in order to filter out idiosyncratic market shocks in the regional return index. The eurozone return index $R_{E, t}$ excluding each individual market $i$ is calculated as $R_{E, t}=\sum_{k \neq i} w_{k, t} R_{k, t}$ where $w_{k}$ is the weight reflecting the market capitalization of each of the other $k$ markets in the eurozone as a proportion of the total euro market comprising those $k$ members.

In preliminary statistical analysis, we found that the distributions of all these national and regional daily stock returns are non-normal. ${ }^{10}$ Both the skewness and the excess kurtosis statistics for these return series are significantly higher than for comparable normal distributions at all meaningful significance levels. The univariate test results of the Ljung-Box Q tests indicate that all return series exhibit highly significant linear and nonlinear serial dependence and point to the presence of high persistence and time varying volatility (heteroskedasticity). Finally, a bivariate version of the Ljung-Box portmanteau test of joint white noise properties rejected joint linear and nonlinear independence at all conventional significance levels, indicating that the first and second moments of the national and regional

\footnotetext{
${ }^{9}$ Datastream's total market indices capture at least 80 per cent of the total market capitalization of a country.
} 
equity returns move closely together. Henceforth, modeling of these return series must address the bivariate and leptokurtic nature of these distributions in addition to the high degree of linear and nonlinear serial correlations.

An appropriately specified GARCH model with a non-normal conditional density for the residuals is suitable for modeling these daily compounding return series to capture the significant levels of excess kurtosis exhibited. Thus, we use bivariate $t$ densities to model excess kurtosis in the standardized residuals from the model and adopt a bivariate version of Nelson’s (1991) exponential GARCH (EGARCH) approach to address the asymmetric nature of volatility responses in the stock return series. There is a well-established need in the stock market volatility literature to look at the effects of asymmetric shocks and previous studies have found that the logarithmic specification in EGARCH models with a suitable distributional assumption fits financial data well. ${ }^{11}$ We show below how the EGARCH framework has been used to model the dynamics of stock market returns.

\subsection{Econometric modeling}

Our aim is to examine whether the establishment of a currency union has induced a dynamic change in stock market integration by making inferences from the behaviour of daily conditional volatility of stock index returns and their conditional correlations. There is much evidence to support the notion that financial market integration changes the conditional return generating process. ${ }^{12}$ Markets are permanently in motion and comovements fluctuate on a daily basis, and so by allowing for asymmetric response characteristics in stock returns, the

\footnotetext{
${ }^{10}$ The table of descriptive statistics has been omitted due to space constraints but is available upon request.

11 By formulating the conditional variances in logarithmic terms, the EGARCH model overcomes the need for non-negativity constraints to ensure positive definite covariance matrices.

${ }^{12}$ See Bekaert and Harvey (2003).
} 
integration process of a member state with the currency union region as a whole is better captured. In recent times, multivariate GARCH models have been extended to incorporate time varying correlations and this feature is theoretically appealing for assessing dynamic financial market integration. Thus, we jointly model pairs of national and regional stock index returns in a parsimonious bivariate EGARCH(1,1)-t model.

In this paper, the conditional first moments (means) of the stock market index returns are estimated as a parsimonious restricted bivariate $\operatorname{ARMA}(p, q)^{13}$ process in order to capture the dynamics between mean stock market returns for each individual country and the eurozone $^{14}$

$$
\begin{aligned}
& R_{N, t}=\alpha_{c N}+\sum_{i=1}^{p_{E}} \alpha_{r E, i} R_{E, t-i}+\sum_{j=1}^{q_{N}} \alpha_{N, j} \varepsilon_{N, t-j}+\varepsilon_{N, t} \\
& R_{E, t}=\alpha_{c E}+\sum_{i^{*}=1}^{p_{N}} \alpha_{r N, i^{*}} R_{N, t-i^{*}}+\sum_{j^{*}=1}^{q_{E}} \alpha_{E, j^{*}} \varepsilon_{E, t-j^{*}}+\varepsilon_{E, t}
\end{aligned}
$$

With

$$
\varepsilon_{t}=\left[\begin{array}{l}
\varepsilon_{N, t} \\
\varepsilon_{E, t}
\end{array}\right] \sim t\left(0, H_{t}, d\right), H_{t}=\left[\begin{array}{cc}
h_{N, t} & h_{N E, t} \\
h_{E N, t} & h_{E, t}
\end{array}\right]
$$

In essence, $R_{N, t}$ is the national conditional mean return that is a function of past returns in the rest of the eurozone and past idiosyncratic shocks, $\varepsilon_{N, t}$ and $R_{E, t}$ is the regional conditional mean return for the eurozone that is a function of past national returns and its own past shocks, $\varepsilon_{E, t}$. Specifically, the regional and country mean spillover effects can be quantified by the sign and magnitude of the estimated coefficients for the lagged eurozone and national

\footnotetext{
13 A bivariate exponential GARCH in mean (EGARCH-M) estimation was also conducted with no improvements in the qualitative results and has been omitted in this paper due to space constraints.

${ }^{14}$ With the exception that lagged US returns were used as 'contemporaneous returns' because the US market opens and closes after European stock markets and therefore affects the Eurozone only on the following day.
} 
returns respectively. Note that $p_{N}$ and $p_{E}$ are the number of autoregressive terms and $q_{N}$ and $q_{E}$ are the number of moving average terms needed to eliminate joint linear and nonlinear serial correlation in the standardized residuals, $\frac{\varepsilon_{N, t}}{\sqrt{h_{N, t}}}$ and $\frac{\varepsilon_{E, t}}{\sqrt{h_{E, t}}}$ which are jointly $t$ distributed.

The conditional second moments (variances) of the estimated model also incorporate interdependencies in the innovations of national and regional stock market returns as shown below:

$$
\begin{aligned}
& \ln h_{N, t}=\beta_{c N}+\beta_{h N} \ln h_{N, t-1}+\left[\beta_{\varepsilon N 1} \frac{\varepsilon_{N, t-1}}{\sqrt{h_{N, t-1}}}+\beta_{\varepsilon N 2}\left(\frac{\left|\varepsilon_{N, t-1}\right|}{\sqrt{h_{N, t-1}}}-\sqrt{\frac{2}{\pi}}\right)\right]+ \\
& {\left[\beta_{E 1} \frac{\varepsilon_{E, t-1}}{\sqrt{h_{E, t-1}}}+\beta_{E 2}\left(\frac{\left|\varepsilon_{E, t-1}\right|}{\sqrt{h_{E, t-1}}}-\sqrt{\frac{2}{\pi}}\right)\right],} \\
& \ln h_{E, t}=\beta_{c E}+\beta_{h E} \ln h_{E, t-1}+\left[\beta_{\varepsilon E 1} \frac{\varepsilon_{E, t-1}}{\sqrt{h_{E, t-1}}}+\beta_{\varepsilon E 2}\left(\frac{\left|\varepsilon_{E, t-1}\right|}{\sqrt{h_{E, t-1}}}-\sqrt{\frac{2}{\pi}}\right)\right]+ \\
& {\left[\beta_{N 1} \frac{\varepsilon_{N, t-1}}{\sqrt{h_{N, t-1}}}+\beta_{N 2}\left(\frac{\left|\varepsilon_{N, t-1}\right|}{\sqrt{h_{N, t-1}}}-\sqrt{\frac{2}{\pi}}\right)\right]}
\end{aligned}
$$

It is assumed that the conditional variance is determined by its own past variance, its own negative and positive past unanticipated shocks as well as those from the other stock index return. In this context, the regional and country volatility spillover effects can be measured by the magnitude of the estimated coefficients for the negative and positive lagged external innovations in the latter part of equations (2) and (3). Instead of assuming constant correlation between the national and regional stock index return series, as in Bollerslev (1990) and many others, we allow it to vary across time to capture the time varying nature of the stock market integration process. The conditional covariance specification is: ${ }^{15}$

\footnotetext{
${ }^{15}$ Alternative covariance structures were estimated as to ensure that the results obtained were robust to different functional forms for the conditional covariance equation. Furthermore, Darbar and Deb’s (2002) logistic
} 


$$
h_{N E, t}=\delta_{0}+\delta_{1} \sqrt{h_{N, t} \cdot h_{E, t}}+\delta_{2} h_{N E, t-1}
$$

where the dynamics of comovement have been modeled based on the cross-product of standard errors of the national and regional stock index returns and past conditional covariance. Hence, the time varying conditional correlations can be computed as the standardized conditional covariances:

$$
\rho_{t}=\frac{h_{N E, t}}{\sqrt{h_{N, t} \cdot h_{E, t}}}
$$

and can be used to indicate the level of comovement between national and regional stock index returns. Specifically, this measures the contemporaneous conditional correlation between the two series and has been used in this paper to provide an indirect measure on the degree of integration between the stock market in a member state and stock markets in the rest of the eurozone. Moreover, this has also been used to gauge the extent of inter-regional integration between stock markets in Europe and Japan and also Europe and the USA. This second application of our empirical model provides invaluable insight into the globalization phenomenon of the past decades.

Finally, the bivariate ARMA-EGARCH-t model is implemented for the stock index returns data via maximum likelihood estimation of the following log likelihood function ${ }^{16}$

$$
L_{T}\left(\theta_{f}\right)=\sum_{t=1}^{T} l_{t}\left(\theta_{f}\right)=\sum_{t=1}^{T}\left[\begin{array}{l}
-\left(\frac{k}{2}\right) \log (2 \pi)-\frac{1}{2} \log \left(\frac{d-2}{d}\right)-\frac{1}{2} \log \left|H_{t}\right|-\frac{k}{2} \log \left(\frac{d}{2}\right) \\
+\log \Gamma\left(\frac{d+k}{2}\right)-\log \Gamma\left(\frac{d}{2}\right)-\left(\frac{d+k}{2}\right) \log \left(1+\frac{\varepsilon_{t}^{\prime} H_{t}^{-1} \varepsilon_{t}}{d-2}\right)
\end{array}\right]
$$

EGARCH was used to explicitly constrain estimated conditional correlations $(-1,1)$. There were no major differences in estimated conditional correlations.

\footnotetext{
${ }^{16}$ The Simplex algorithm was first used to determine appropriate starting values for parameter estimates then numerical optimization was based on the Broyden, Fletcher, Goldfarb and Shanno (BFGS) algorithm.
} 
where $\mathrm{k}=2$ in the bivariate case, $\theta_{f}$ is the vector of parameters to be estimated, $\mathrm{T}$ is the number of observations. As discussed above, a conditional bivariate student's $t$ distribution with variance-covariance matrix $\mathrm{H}_{t}$ and $d$ degrees of freedom has been assumed for the joint distribution of the two error processes instead of the standard bivariate normal distribution in order to account for possible leptokurtosis in the joint conditional densities (see Bollerslev, 1987). The advantage of employing this distribution is that the unconditional leptokurtosis observed in most high-frequency asset price data sets can appear as conditional leptokurtosis and still converge asymptotically to the Normal distribution as $d$ approaches infinity (usually in lower-frequency data). As shown below, this is well suited for the dynamics of those stock market returns employed.

\subsection{Empirical Results}

In general, the bivariate EGARCH model $^{17}$ was found to be appropriate for all the index return pairs as significant negative asymmetric effects $\left(\beta \varepsilon_{N 1}, \beta_{E 1}, \beta \varepsilon_{E 1}\right.$ and $\left.\beta_{N 1}\right)$ together with positive volume effects $\left(\beta \varepsilon_{N 2}, \beta_{E 2}, \beta \varepsilon_{E 2}\right.$ and $\left.\beta_{N 2}\right)$ were present. Furthermore, the coefficients for the lagged conditional volatility $\left(\beta_{h N}\right.$ and $\left.\beta_{h E}\right)$ were close to one for all countries suggesting a high persistence in shocks to the conditional volatility. The Ljung-Box Q statistics indicated that joint linear and non-linear serial correlations in the standardized residuals had been successfully eliminated in the bivariate ARMA-EGARCH-t models.

Figures 1 and 2 illustrate the path of time varying conditional correlations estimated from these bivariate EGARCH models for the twelve EMU members and the other five noneuro countries. Due to the differences in the industrial structure of the underlying stock

\footnotetext{
${ }^{17}$ As requested by the editor, the full results and diagnostic tests are not reported due to space constraints. They are available upon request.
} 
market indices, the levels of comovement in stock returns will differ. By construction, countries such as Germany, France and Italy with larger stock market capitalizations will appear to be more integrated with the EMU regional core and this is reflected in the levels of conditional correlations in Figures 1 and 2. Nevertheless, it is clear that the pattern of stock market integration has varied strongly over time for all EU countries, having been more volatile prior to the mid 1990s. In the aftermath of the severe and costly EMS crisis over 1992-93, stock markets in the region were to some extent heading towards further segmentation (reflecting the general state of uncertainty surrounding the single currency project) but this had stabilized in all EU countries by 1996. Since 1996-97 there has been a clear change in the dynamics of integration amongst stock markets inside the entire EU (not just amongst those members that have adopted the euro) and the long-run trend towards regional integration is obvious. We note that from 1996 to late 1998, integration increased rapidly for most EU members. This period coincided with the final stages of the Treaty of Amsterdam in which political and institutional conditions were created to enable the EU to meet the challenges of the future with amendments to the Maastrict (EU) Treaty. This was a major milestone in the path to integration as it eliminated a large amount of uncertainty leading up to the formal adoption of the euro and consequently kicked off the distinct upward trend in stock market integration for all EU countries. The phase of uncertainty preceding this phase of rapid integration is clearly more pronounced for Portugal, Ireland, the Netherlands and Greece. Interestingly, late entry has not been a major setback for integration of Greece's stock market into the EMU. As previous European stock market studies have recognized, stock prices move in anticipation of future events and forward looking investors had already factored in the introduction of the euro into stock prices prior to its formal introduction (eg. Morana and Beltratti, 2002). A long lasting benefit since 1999, has been the effective stabilization of the integration process as indicated by dampened volatility in all estimated 
conditional correlation series. This is possibly due to the stabilization in macroeconomic fundamentals through the EMU convergence process as shown by Morana and Beltratti (2002). The view of these authors is that the introduction of the euro was "a macroeconomic news of varying importance for different countries which in no case has brought about a revolution in the economic structure.” Although to some extent, the changes in the integration patterns do vary amongst all the EU countries in line with this view, there is stark evidence that a regime shift has occurred under the currency union in most member states that have adopted the euro. This change is clearer in our more recent sample period than in earlier studies. While Morana and Beltratti (2002) have focused on the changes in stock return volatility specifically before and after the introduction of the euro, our focus is on the overall changes in stock market comovements with the eurozone. It is clear that a new regime marked by increased stability and higher mean levels of integration has emerged for EMU countries in the post-euro era.

On the global front, ties between the euro region and the other two major markets were also strengthened during this period of monetary unification and is consistent with the general evolution towards more integrated financial markets documented by Ayuso and Blanco (2001) and Carrieri et al. (2001). ${ }^{18}$ However, heterogeneity is evident between the eurozone and non-eurozone stock markets as there are important differences in their conditional correlation time series in our sample period. To the extent that investors did update their stock valuations leading up to the macroeconomic "news" regarding the formal introduction of the euro in the EU market, the anticipation was not as significant outside the EU, particularly in the Japanese stock market where there is much more noise in the

\footnotetext{
${ }^{18}$ Although these authors argue that higher correlations of market-wide index returns are neither a necessary nor sufficient condition for greater market integration.
} 
conditional correlation series, as seen in Figure 2. Specifically, a regime shift in integration with the EMU is not obvious although the pattern is consistent with stock market integration inside the eurozone in that there was also an upward trend preceding the euro's formal introduction as the uncertainties were reduced and a plateau has also emerged in the post-euro period. Quantifying the linkages between stock market returns will further aid our assessment on the differences in regional and global integration.

\subsection{Conditional mean and volatility spillover effects}

Spillovers in mean return and volatility occur when past information from the stock markets in the member country or the euro area (outside of that member) has persistent effects on the other. The coefficients of the mean spillover variables (lagged cross-market returns) and the spillovers in negative and positive unexpected cross-market shocks have been isolated in Tables 1 and 2 respectively. They have been estimated for the full sample period as well as three sub-samples ('integration phases') justified on the basis of observed integration patterns. The first sub-sample period (January 1989 to December 1995) indicates the phase before major changes took effect in the integration process of these equity markets. The second subsample is the short intense pre-euro integration phase between January 1996 and December 1998. The third sub-sample (January 1999 to May 2003) is the extended post-euro phase. In such an exercise, the econometric model that is suitable for the full sample may not necessarily be a good fit for individual sub-samples. However, a break down of the full sample period contributes to our understanding of the long-term dynamics of the stock market integration process.

In Table 1, we note that the sign of the significant coefficients from individual lagged country returns (country spillover effect) may be positive or negative but the coefficient from 
the eurozone (regional spillover effect) is always positive. This could simply be attributed to the law of averages in that the idiosyncratic differences in information transmission are more predictable for the value-weighted average of the whole eurozone. Based on the magnitudes of these significant regional spillover coefficients, for an equal percentage increase in stock returns for the rest of the eurozone, stock returns in the US stock market will move the most $(0.426 \%)$ in the same direction, followed by the German $(0.289 \%)$ then Japanese stock market $(0.248 \%)$ on the next day. The sensitivity of the US and Japanese stock markets to information flows from the eurozone is another indicator that globalization is a key feature of the $21^{\text {st }}$ Century. It should also be noted that of all the countries in the sample, only Luxembourg required more than one lag in the regional mean return to fully eliminate serial correlation in its conditional mean equation. This suggests that this stock market is the most inefficient at incorporating information into stock prices. It is also revealed in Table 1 that changes in stock market returns for the eurozone are led by stock market returns in France, the UK, Spain and the Netherlands whilst stock market returns for the euro region react in an opposite direction to developments in Japan, the US and Denmark, Austria, Ireland, and Portugal.

As is evident in Tables 1 and 2, regional spillovers in mean returns and unexpected shocks tend to be larger than the country specific spillover effects. This is an intuitive result given the size difference of these sources. In regards to return spillovers reported in Table 1, the effects are not constant. The magnitude of these linkages has increased for most countries in line with the three distinct phases in stock market integration. As integration in stock markets proceeded, the interdependencies between national and eurozone stock markets have strengthened, although not always in the same direction. Feedback effects in country and regional returns are apparently asymmetric in that information may spillover unidirectionally from a country into the euro region or vice versa. As expected, for most countries these 
feedback effects are bidirectional. The volatility spillovers reported in Table 2, suggest that European markets are largely integrated as the regional shocks appear to be relatively larger than the country specific shocks and are becoming increasingly more so. The asymmetric and volume effect from the past unexpected shock from each individual country and from the euro region are mostly significant and of the appropriate sign over the full sample period but not for all sub-sample periods.

In short, linkages between stock markets inside and outside of the Euro region are clearly present and have strengthened following currency unification. The significant spillover coefficients indicate the EMU members are crucial both to each other's prosperity and to the stability of the world economy as a whole. It can be inferred from these results that the benefits of portfolio diversification across international stock markets have decreased in recent times. This is not only consistent with the findings of increased correlations in crosscountry stock returns documented by Longin and Solnik (1995) but more importantly the findings by Freimann (1998) and Beale (2004) on reduced diversification benefits in European stock markets with increased regional economic integration. Given so, what are the specific determinants of stock market integration? Are there particular factors related to the EMU that are driving stock markets to be more integrated? If so, a better understanding of these factors would not only assist portfolio managers and investors but also guide policy makers in the direction of more efficient financial markets.

\section{The Determinants of stock market integration}

In this section, we build on the work already presented and we utilize a two step estimation methodology to find the main determinants of stock market integration. First, we present the arguments for potential determinants selected. Following that, we test for causality 
between stock market integration and European currency unification to facilitate an appropriate modeling strategy. Finally, our empirical methodology and results will be discussed in detail.

\subsection{Potential explanatory variables for stock market integration}

To substantiate the link between stock market integration and the EMU we first test the significance of a euro dummy in explaining the previously estimated conditional correlation time series. We believe that a euro dummy (taking the value of one from 1 January 1999 and zero otherwise) is the broadest proxy for the introduction of the euro and can be used as a first assessment in regression analyses.

It has also been recognized in the literature that what drives time variations in financial market integration may not only be a country's own economic performance, but also the degree of real and financial linkage with other economies (Fratzscher, 2002, Yang et al., 2003 and Baele, 2004). The Optimal Currency Area (OCA) literature pioneered by Mundell (1961) and McKinnon (1963) offers several assessment criteria for the suitability of countries for a common currency area. There are three broad channels identified in the literature through which a currency union can directly affect financial market integration and we will build on these and introduce other variables in a linear systems regression to determine the driving forces behind the regional and global integration of stock markets in the EMU.

Firstly, given that currency risk premia has been priced in most international asset pricing models since the seminal paper by Solnik $(1974)^{19}$, it has been recognized that currency risk premia can be interpreted as a major impediment to financial integration and

\footnotetext{
${ }^{19}$ Also see Dumas and Solnik (1995) and DeSantis and Gerard (1998)..
} 
that the launch of a common currency directly eliminates most intra-union currency risk. ${ }^{20}$ Although, elimination of intra-union exchange rates with the introduction of the euro has been shown by Morana and Beltratti (2002) in a theoretical variance decomposition of shocks to excess returns to cancel out components of exchange rate risks borne by a domestic investor holding foreign stock under a different currency, they argue that because the covariance between exchange rates and stock returns is empirically small, elimination of intra-union currency risk has not affected European stock markets. However, Fratzscher (2002) and Baele (2004) provides empirical evidence that exchange rate stabilization has been important for stock market integration in Europe. We seek to resolve this disparity on exchange rate risk as we believe that this is a vital issue relating to stock market integration and currency unions. Theoretically, interdependent movements (estimated conditional correlations) between the individual national stock market returns should increase as foreign exchange volatility has reduced (inverse relationship).

Secondly, as EMU members knew in advance that they were required to meet various economic convergence criteria for EMU entry from the 1992 Maastrict (EU) Treaty, a significant degree of convergence had occurred in their real economies. It has long been found that business cycle conditions are intricately linked with asset returns (see Fama and French, 1989 and Rouwenhorst, 1995) and international equity correlations (see Erb et al., 1994). If countries are in similar phases of the business cycle, the degree to which shocks are transmitted across financial markets will be increased. Thus, we expect a priori, increases in real convergence (via growth rates in industrial production) will stimulate higher stock market integration.

Finally, the EMU integration process has also been characterized by monetary policy convergence in that independent monetary policies have been replaced by a single one for all

\footnotetext{
${ }^{20}$ A single currency zone is equivalent to a system of irrevocably fixed exchange rates.
} 
EMU members. For this reason, Morana and Beltratti (2002) also showed that the variance of interest rates have reduced through the convergence of monetary policies and attributed the decline in volatility of European stock markets mainly to the stabilization of fundamentals and expectations thereof. Hence, we anticipate a priori that monetary policy convergence (via short term interest rates and inflation rates) has also increased stock market integration.

In addition to these, we introduce control variables used in standard asset pricing studies to ascertain the true importance of these currency union variables. Our control variables include country specific aggregate stock market liquidity and development measures and other seasonal anomalies that might change stock market returns and hence, comovements. We test for the significance of domestic financial development as commonly measured by stock market capitalization as a proportion of Gross Domestic Product (GDP) and liquidity as proxied by the logarithm of turnover by volume. In addition, we test for a day of the week effect using a Friday dummy and the turn of the year effect using a January dummy. ${ }^{21}$ Data used in all constructed variables were sourced from Datastream. Before these variables can be tested, we must establish the existence and nature of causality between the European currency union formation and observed stock market integration.

\subsection{Direction of causality: Stock market integration and currency union}

Although we have documented stock market integration in the period characterized by the introduction of the euro and beyond, it does not explicitly provide evidence of a causal relationship. To our knowledge, the causality issue between financial market integration and currency unification has never been addressed in the international finance literature. Indeed, questions remain about causality: do currency unions drive financial market integration in that

\footnotetext{
${ }^{21}$ A Monday dummy was also initially included but it was insignificant for all countries.
} 
a political decision to form a currency union could anchor exchange rate expectation and create incentives to establish integrated capital markets or does financial integration create more incentives for joining a currency union, or both? Although logic supports the former, economic theory purports that financial market integration promotes risk sharing benefits through asset markets and this may create economic incentives for countries to join a currency union and give up control of their monetary policy. Optimal currency area (OCA) theory clearly suggests that as integration proceeds, monetary unions will become more desirable as the costs for foregoing an independent monetary policy are higher for countries that are prone to asymmetric shocks. Given that each member state has unique challenges based upon its own degree of diversification in production (industry mix), economic, cultural, legal, political and social institutions, causality from financial market integration to currency unification is also a reasonable assumption. Alternatively, there may not be causality either way but instead, independence. It is clear that there is a need for deeper understanding of stock market integration in currency unions.

To address this issue, the Granger causality test was conducted between the previously estimated time varying conditional correlations $\left({ }^{\wedge} T_{t}\right)$ and a euro dummy $\left(E M U_{t}\right)$, taking a value of one from January 11999 and zero otherwise. ${ }^{22}$ We used various lag structures (2, 4, 6 and 8) for each of the individual countries, and found that there exists a uni-directional relationship running from the EMU to the stock market integration. The first null hypothesis $\left(E M U_{t}\right.$ does not cause $\left.I N T_{t}\right)$ was rejected for all euro and non-euro countries at the $10 \%$

\footnotetext{
${ }^{22}$ As suggested by the anonymous referee, details of the test construction and the results need not be reported due to its unambiguous nature. They are available upon request. For robustness, we also used correlations in short-term interest rates as a proxy for the EMU, and the results were not qualitatively different. An alternative euro dummy was used for Greece, taking a value of 1 for dates after 1 January 2001 (Greece's formal entry into the EMU).
} 
significance level but not for France, Spain, Austria, nor Finland at the 5\% level. However, the second null hypothesis ( $I N T_{t}$ does not cause $E M U_{t}$ ) could not be rejected for all meaningful significance levels. Our simple analysis provides a better understanding of the path to financial market integration on both a regional and global scale. There is consistent evidence across our sample countries to show that the currency regime is necessary for financial market integration as the EMU Granger caused stock market integration between all euro members. Furthermore, the EMU has also Granger caused financial integration of the EMU vis-à-vis Japan and the US. These results are not only illuminating but also helpful for finding a suitable model specification to determine the true extent to which the EMU is driving the time varying integration process in stock markets. We will account for this oneway direction of causality in the following section.

\subsection{Methodology and empirical evidence: Explaining stock market integration}

Given the upward trend in most integration (conditional correlation) series estimated from the bivariate EGARCH model, tests for non-stationarity were first conducted to determine the appropriate model for our dependent series. The results from unit root tests are shown in Table 3. The null hypothesis of the presence of a unit root in each of the dependent series for the 12 EMU countries and for Japan and the US are rejected at the conventional 5\% significance level. However, Ljung-Box Q test statistics revealed these dependent series to be highly autocorrelated, necessitating the inclusion of lags of these series in the econometric models in addition to Newey-West (1987) corrections for hetereoscedasticity and serial correlations. $^{23}$

\footnotetext{
${ }^{23}$ Serial correlation in a regression model with lagged dependent variables can potentially bias the estimators.
} 
Single equation ordinary least squares (OLS) and seemingly unrelated regression estimations (SURE) have been sequentially applied to determine the drivers of the stock market integration process in the sample countries and the results are shown in Table $3 .{ }^{24}$ The assumption under SURE is that the error terms in a system of equations at any point in time are contemporaneously correlated because they are capturing similar effects. This is reasonable for our EMU and non-EMU countries given that these error terms contain the influence of omitted factors on their respective integration process eg., regulatory barriers, political, institutional, social and cultural factors. Since the members are similar in nature due to economic convergence required by the Maastrict (EU) Treaty, it is conceivable that the effects of the omitted variables on each country's integration will be similar. Hence, additional information normally excluded from separate least squares estimation of the equations is captured by this assumption. Contemporaneous correlations between error terms have been utilized to produce better estimates by jointly estimating these equations within a joint generalized least squares (GLS) framework. ${ }^{25}$

Building on from the Granger Causality tests, we attempt to substitute the euro dummy with proxies for the three main channels through which the EMU has potentially affected stock market integration - namely, reduction in currency risk, convergence in the real economy and also in monetary policies. ${ }^{26}$ In this study, we thoroughly weight all individual members to measure convergence in real and monetary terms with regional EMU levels. In

\footnotetext{
${ }^{24}$ OLS results have been omitted due to space constraints but are available upon request. OLS is not appropriate for our $2^{\text {nd }}$ pass regression analysis due to our constrained (by definition) dependent variable.

${ }^{25}$ We performed correlation analyses between the residuals in each equation as reported in Tables 4 and 5 . The results revealed fairly high correlations (average of 0.61 for the Table 4 estimations and 0.64 for the Table 5 estimations) providing justification for using SURE. These results are available upon request.

${ }^{26}$ Unlike Fratzscher (2002) who uses principal component analyses, we use individual proxies to facilitate more meaningful interpretation of estimated coefficients.
} 
the existing literature, convergence towards Germany has been commonly assessed as Germany is considered to be an anchor country to which other members in the union converge towards. However, given that economic performance between member states have been diverging in recent times, a weighted average of all members would be a better proxy for regional levels and provide a more accurate assessment of convergence due to the EMU. We recognize that in our attempt to explicitly model the different facets of currency unification, a degree of joint endogeneity may be introduced in that these changes coincided with the process of stock market integration in the transition period leading up to the EMU and also with each other. Thus, a degree of multicollinearity may also be introduced which potentially invalidates the inference of the estimators. Given the evidence on unidirectional causality from the monetary union to stock market integration, the independent variables that are not dummy variables have been lagged by one day in the regressions to separate the different contemporaneous sources of integration and to minimize bias in our estimated coefficients. Preliminary correlation analyses also suggest that multicollinearity is not of major concern in our models. ${ }^{27}$ Furthermore, to provide accurate estimates on the relative importance of these explanatory variables, we control for stock market liquidity and financial development and other confounding seasonal anomalies that might influence stock market returns. Specifically, we estimate the following equation as a linear system for all EMU members and then for Japan and the US using SURE:

$$
\begin{aligned}
& \hat{I N T}_{i, t}=\beta_{1 i}+\beta_{2 i} E X_{-} V O L_{i, t-1}+\beta_{3 i} \text { OUTPUT }_{i, t-1}+\beta_{4 i} \text { IRATE }_{i, t-1}+\beta_{5 i} \text { FIN }_{-} \text {DEPTH }_{i, t-1} \\
& +\beta_{6 i} \log (V O L)_{i, t-1}+\beta_{7 i} F R I_{-} D U M_{i, t}+\beta_{8 i} J A N_{-} D U M_{i, t}+\beta_{9 i} I N T_{i, t-1}+\beta_{10 i} I N T_{i, t-2}+u_{i t}
\end{aligned}
$$

\footnotetext{
${ }^{27}$ Correlation matrices for all explanatory variables used in the regressions for each country have not been included due to space considerations but are available from the authors upon request.
} 
where the dependent variable $\left(\hat{I N T_{i t}}\right)$ is the estimated conditional correlation series for each country $i, E X \_V O L=$ conditional exchange rate volatility, OUTPUT $=$ correlations in the growth of seasonally adjusted industrial production rates with euro area GDP weighted averages, IRATE = correlations in nominal short term (30 day) interest rates with Euro area GDP weighted averages, FIN_DEPTH = ratio of stock market capitalization to GDP, $L O G(V O L)=$ logarithm of the stock market's turnover by volume, FRI_DUM and JAN_DUM are the seasonal dummies introduced before and $I N \hat{T}_{i, t-1}^{\wedge}$ and $I N T_{i, t-2}^{\wedge}$ are the first and second lags of the dependent variable. ${ }^{28}$ It should be noted that EX_VOL is derived from fitting a GARCH(1,1) process to daily local currency to ECU exchange rate returns.

The SURE results from this specification are shown in Table 3 and summarized in Table 4. From a statistical perspective, the model is adequate in explaining the variations in the integration series. While the adjusted R-squares are close to one in the presence of two autoregressive terms used to eliminate serial correlation, they fall to around 0.3-0.4 (accompanied by excessive serial correlation) in their absence. Furthermore, significance of explanatory variables suggests that multicollinearity is not a problem in our model specification. From the economic perspective, most of the significant estimated coefficients have the expected signs. The intercept terms are significant and positive in most cases. Consistent with the initial specification, at least one of the two financial control variables (log of Volume and Financial depth) is positively significant for most countries in the EMU. This reinforces our belief that stock market integration is largely dependent on the existing size and level of financial development and is consistent with Carrieri et al.'s (2001) findings for the integration of emerging stock markets and Baele’s (2004) assessment of European stock

\footnotetext{
${ }^{28}$ For robustness, a detrended volume variable was also used in equation (7). On the basis of Q stats, we find that two lags sufficiently eliminate most of the serial correlation for all countries in our estimations.
} 
markets. The Friday dummy is insignificant for all countries whilst the January effect is significant for Japan and Ireland, Portugal, Austria, Luxembourg and Greece indicating a seasonal component in comovements. Contrary to Karolyi and Stulz’s (1996) study on stock market comovements between Japanese and US markets, we find little evidence of day of the week effects once economic convergence variables are included. These are indeed new findings for integration in European stock markets.

Contributions made by the three different mechanisms of the monetary unification have varied for member states in the union and there are some differences in our results with existing studies due to our systems estimation approach. Reductions in conditional foreign exchange volatilities have only been important to stock market integration for the Netherlands and the two smaller countries, Luxembourg and Greece as indicated by the negative and significant coefficients. Our results appear to be a compromise between the theoretical arguments made by Morana and Beltratti (2002), Fratzscher’s (2002) and Baele’s (2004) empirical findings as we find exchange rate stability has only been important for the integration of some stock markets and not all. Our empirical results lend more support to the argument that changes in stock market comovements are not primarily due to changes in currency risk premia, consistent with Bodart and Reding's (1999) finding that correlations in stock returns are not very sensitive to the exchange rate regime. This makes intuitive sense given that exchange rates have been required to fluctuate within narrow bands from a basket of European currencies (ECU) since 1979. This makes the euro a close substitute for the original currencies of most major EMU countries anyway. Our results show that it is only in those smaller member states with fundamentally different economic structures, where the reduction in exchange rate risk has spurred integration in their stock markets. Our results for the other two EMU variables are not directly comparable with Fratzscher's (2002) findings as we have not used the principal component approach. Nevertheless, we are shedding light on 
the importance of the proxies which we have used. Real convergence via growth in industrial production appears to have provided impetus for the integration process in Italy, Portugal, Austria and to a lesser extent Japan. Finally, convergence towards a single interest rate has only been significant and beneficial for Italy. These results are consistent with the existing evidence that reductions in the volatility of macroeconomic fundamentals associated with the euro's introduction have been the key reason behind calmer stock market volatility in Italy (Morana and Beltratti, 2002). In addition, insignificance of the economic convergence factors in the larger EMU countries corroborate with Baele's (2004) finding that economic integration intensified European shock spillovers in the second part of the 1980s and the first part of the 1990s. Hence, economic integration has not continued to drive economic integration in the major stock markets.

An alternative specification estimated for Japan and the US is also shown in Table 5. Correlation in consumer price inflation is used to proxy monetary policy convergence instead of nominal short term interest rates. It is revealed that the commitment of monetary authorities to price stability has been an important factor behind higher levels of comovement between the EMU and the US whilst real convergence has been more important for increasing ties between the EMU and Japan. This suggests that implementation of a single currency area has enhanced supranational economic policy coordination by the European Central Bank (ECB) and has contributed to the phenomenal integration of stock market across regions.

All these results suggest that the increase in stock market integration has been a selffuelling process driven by existing levels of stock market development in the economy. The EMU has played a significant role in stock market integration for those member states with fundamentally different macroeconomic structures or historically volatile stock markets and also on an inter-regional level through more coordinated policy stances. 


\section{Conclusions}

The aim of this paper was to investigate the dynamic nature and determinants of regional and global stock market integration. We have documented that both intra-regional and interregional stock market integration was highly volatile prior to the second half of the 1990s and it had increased rapidly in the two years leading up to the official launch of the euro. Since 1999, the process has been much stronger and more stable than before and with the benefit of a longer post-euro sample period, a regime shift is revealed for integration in all EMU stock markets. As a result, intra-regional and inter-regional return and volatility spillovers have been heightened in the period characterized by the introduction of the euro. We have also managed to shed light on the gaps and disparities in the link between currency unions and financial market integration. In particular, we have established unidirectional causality from the political creation of the European currency union to the integration between stock markets within EMU member states and also with Japan and the US. Moreover, our two step systems estimation approach for the group of EMU members reveals that increasing stock market comovements can be explained with the overall macroeconomic convergence process associated with the introduction of the euro rather than the specific effects of the elimination of foreign exchange rate risk due to the currency unification. However, financial market integration is largely a self-fuelling process dependent on existing levels of financial sector development and is particularly strong during the month of January. In addition, we have found that the contribution of currency stability to stock market integration is only significant for the smaller EMU members with historically different economic structures. As a result of the European Monetary System introduced in 1979, the euro was already a very close substitute for most major European currencies. On a global level, the commitment to price stability has significantly strengthened stock market integration between the EMU and the US 
whilst convergence in the industrial production has increased ties between the EMU and Japan. Although diversification benefits have reduced, the process of financial integration remains incomplete for the smaller member states and opportunities to invest in the eurozone remains. Complete integration of Europe's stock markets will ultimately depend on many factors and the removal of other impediments will take some time.

\section{References}

Ayuso, J., Blanco, R., 2001. Has financial market integration increased during the nineties? Journal of International Financial Markets, Institutions and Money 11(3-4), 265-287.

Baele, L., 2004. Volatility Spillover Effects in European Equity Markets. Journal of Financial and Quantitative Analysis, in press.

Baele, L., Ferrando, A., Hordahl, P., Krylova, E., Monnet, C., 2004. Measuring Financial Integration in the Euro Area. Occasional Paper 14, European Central Bank.

Bekaert, G., Harvey, C.R., 1995. Time-varying world market integration. Journal of Finance $50,403-444$.

Bekaert, G., Harvey, C.R., 1997. Emerging equity market volatility. Journal of Financial Economics 43, 29-77.

Bekaert, G., Harvey, C.R., 2003. Emerging markets finance. Journal of Empirical Finance 10, 3-55.

Bessler, D.A., Yang, J., 2003. The structure of interdependence in international stock markets. Journal of International Money and Finance 22, 261-287.

Bodart, V., Reding, P., 1999. Exchange rate regime, volatility and international correlations on bond and stock markets. Journal of International Money and Finance, 18, 133-151.

Bollerslev, T., 1987. A conditional heteroskedastic time series model for speculative prices and rates or return. Review of Economics and Statistics 69, 542-547.

Bollerslev, T., 1990. Modeling the coherence in short-run nominal exchange rates: A multivariate generalized ARCH model. Review of Economics and Statistics 72, 498505.

Carrieri, F., Errunza, V., Hogan, K., 2001. Characterizing world market integration through time. Working paper, McGill University. 
Chen, G.-M., Firth, M., Rui, O.M., 2002. Stock market linkages: Evidence from Latin America. Journal of Banking and Finance 26, 1113-1141.

Darbar, S.M., Deb, P., 2002. Cross-market correlations and transmission of information. Journal of Futures Markets 22(11), 1059-82.

DeSantis, G., Gerard, B., 1998. How big is the premium for currency risk? Journal of Financial Economics 49, 375-412

Dumas, B., Solnik, B., 1995. The world price of foreign exchange risk. Journal of Finance, 50, 445-479.

Erb, C.B., Harvey, C.R., Viskanta, T.E., 1994. Forecasting international equity correlations. Financial Analysts Journal 50, 32-45.

Eun, C. S. and Shim, S., 1989. International transmission of stock market movements. Journal of Financial and Quantitative Analysis 24(2), 241-256.

Fama, E., French, K., 1989. Business conditions and the expected returns on stocks and bonds. Journal of Financial Economics 25, 23-50.

Forbes, K.J., Chinn, M.D., 2003. A decomposition of Global linkages in financial markets over time. NBER working paper no. 9555.

Forbes, K.J., Rigobon, R., 2002. No contagion, only interdependence: measuring stock market co-movements. Journal of Finance 57(5), 2223-2261.

Fratzscher, M., 2002. Financial market integration in Europe: On the effects of the EMU on stock markets; International Journal of Finance and Economics 7, 165-193.

Freimann, E., 1998. Economic integration and country allocation in Europe. Financial Analysts Journal 54, 32-41.

Glosten, L., Jagannathan, R., Runkle, D. 1993. On the relation between the expected value and the volatility of the nominal excess return on stocks. Journal of Finance 48, 17791802.

Hamao, Y.R., Masulis, R.W., Ng, V.K, 1990. Correlations in price changes and volatility across international stock markets. The Review of Financial Studies 3(2), 281-307.

Hardouvelis, G.A., Malliaropulos, D., Priestley, R., 1999. EMU and European Stock market integration. CEPR Discussion Paper 2124.

Karolyi, G.A., Stulz, R.M., 1996. Why do markets move together? An investigation of U.SJapan stock return comovements. Journal of Finance 51(3), 951-986.

King, M., Wadhwani, S., 1990. Transmission of volatility between stock markets. Review of Financial Studies 3, 5-33. 
Longin, F., Solnik, B., 1995. Is the correlation in international equity returns constant: 19601990? Journal of International Money and Finance 14(1), 3-26.

McKinnon, R.I., 1963. Optimum currency areas. American Economic Review 53, 717-725.

Morana, C., Beltratti, A., 2002. The effects of the introduction of the euro on the volatility of European Stock markets. Journal of Banking and Finance 26, 2047-2064.

Mundell, R.A., 1961. A theory of optimum currency areas. American Economic Review 51, 657-665.

Nelson, D.B. (1991). Conditional heteroskedasticity in asset returns: A new approach. Econometrica 59, 347-370.

Newey, W., West, K., 1987. A simple positive-definite heteroskedasticity and autocorrelation consistent covariance matrix. Econometrica 55, 703-708.

Pagano, M. 1993. Financial Markets and growth: An overview. European Economic Review 37, 613-622.

Prasad, E., Rogoff, K. Wei, S.-J., Kose, M.A., 2003. Effects of financial globalization on developing countries: some empirical evidence. International Monetary Fund, Working paper.

Rouwenhorst, K.G., 1995. Asset pricing implications of equilibrium business cycle models, in: Cooley, T.F. (Ed.), Frontiers of business cycle research. Princeton University Press, Princeton, pp. 294-330.

Solnik, B., 1974. Why not diversify internationally rather than domestically? Financial Analysts Journal 30, 48-54.

Susmel, R., Engle, R.F., 1994. Hourly volatility spillovers between international equity markets. Journal of International Money and Finance 13, 3-25.

Yang, J., Min, I., Li, Q., 2003. European stock market integration: Does EMU matter? Journal of Business, Finance and Accounting 30(9-10), 1253-1276. 
Figure 1. Time varying stock market integration, 2/1/1989-29/5/2003

Time-varying Conditional Correlations inside the EMU

$\left.\begin{array}{l}0.9 \\ 0.7 \\ 0.5 \\ 0.4 \\ 0.3 \\ 0.2 \\ 0.2\end{array}\right]$ cermany
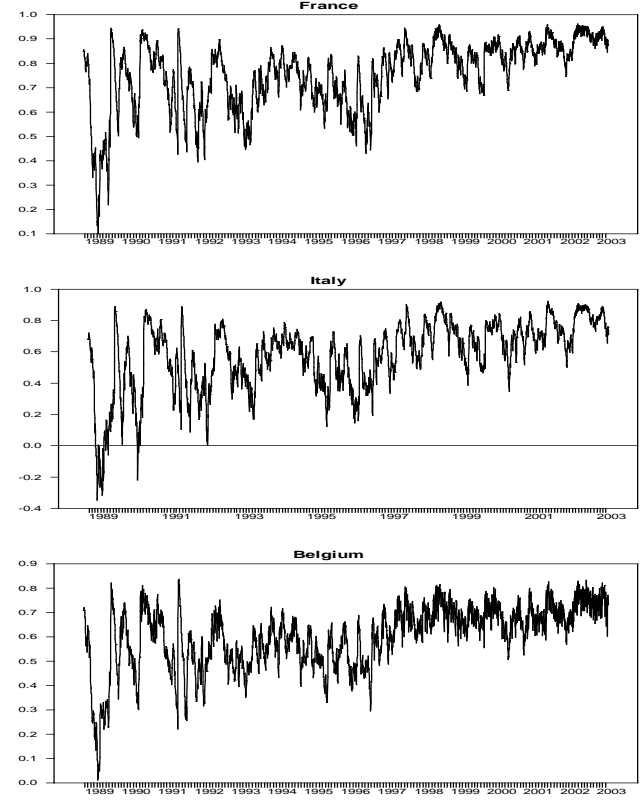
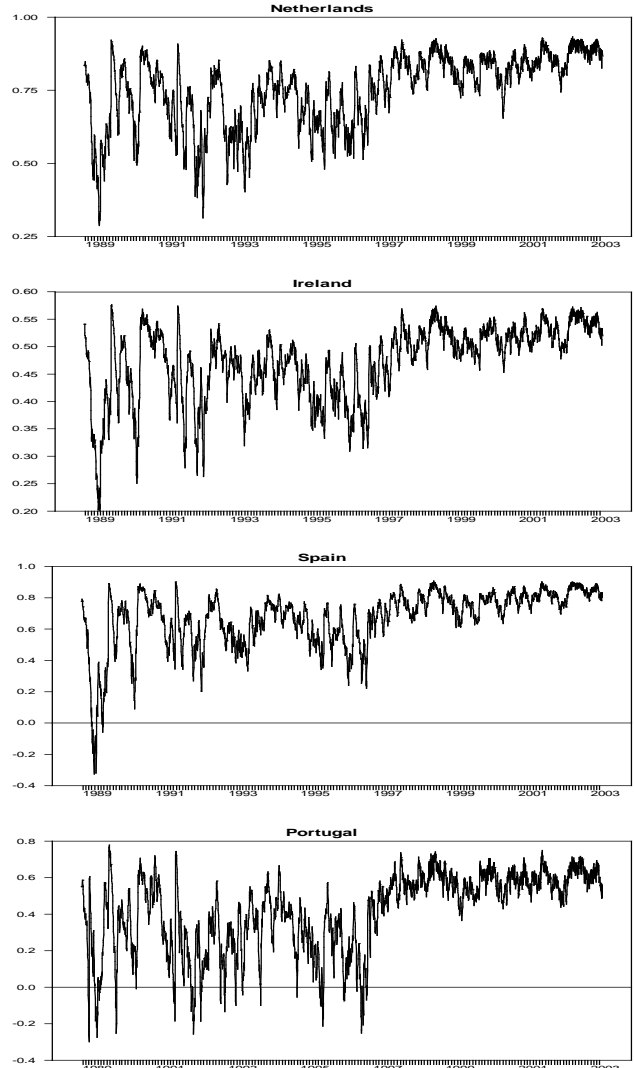
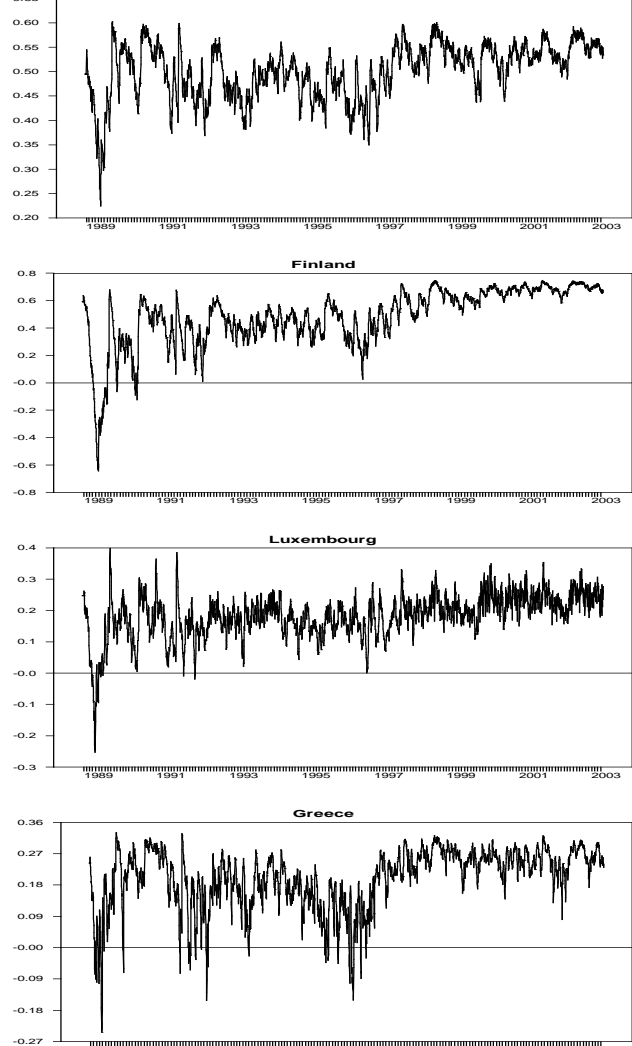
Figure 2. Time varying stock market integration, 2/1/1989-29/5/2003

Time-varying Conditional Correlations outside the EMU

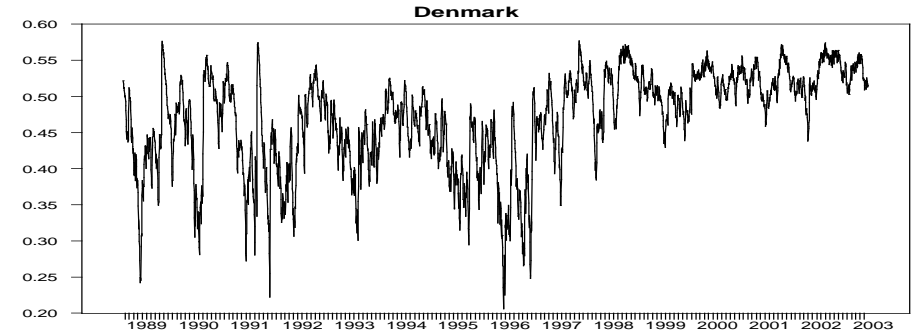

uk

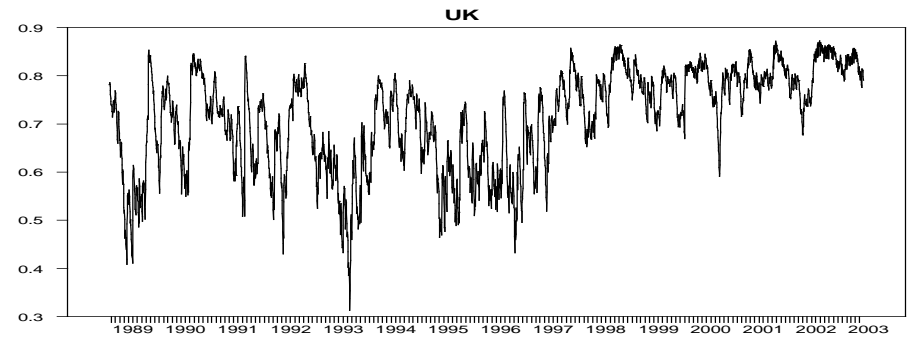

Sweden

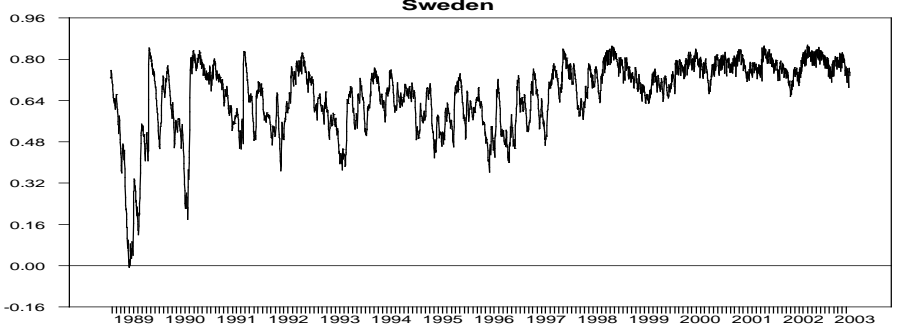

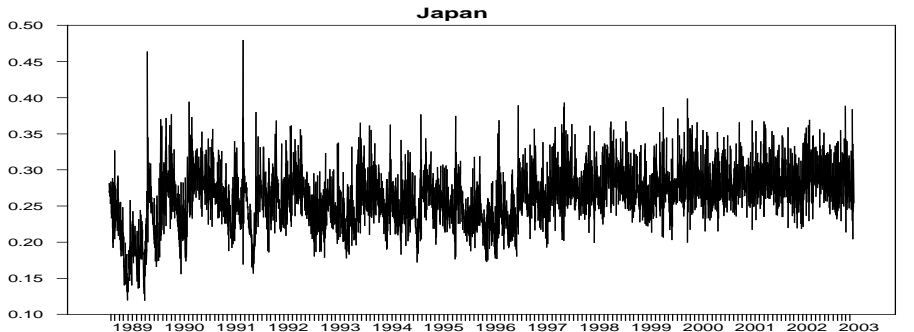

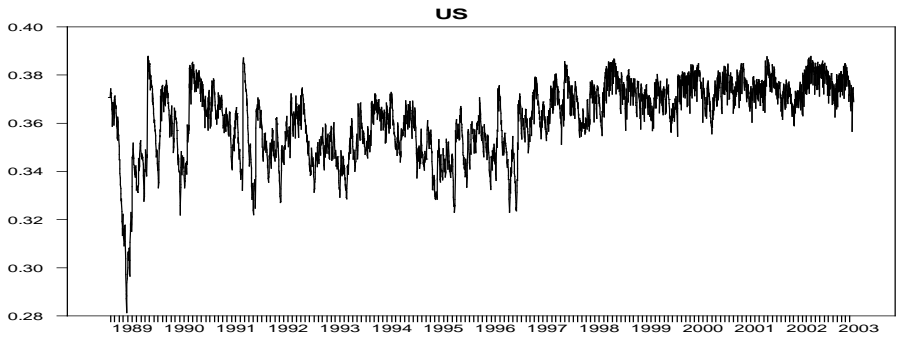

39 
Table 1

\section{Bivariate ARMA-EGARCH-t results for stock market (Mean) return spillovers}

In this table, the estimated mean return spillovers from the national $\left(\alpha_{\mathrm{rN}}\right)$ and regional $\left(\alpha_{\mathrm{rE}}\right)$ stock markets are reported for the full sample period and three other subsample periods shown. Asymptotic p-values are shown in the brackets. *, **, *** denote statistical significance at the 10,5 and $1 \%$ level respectively. The conditional mean equations, as defined in equation (1), is

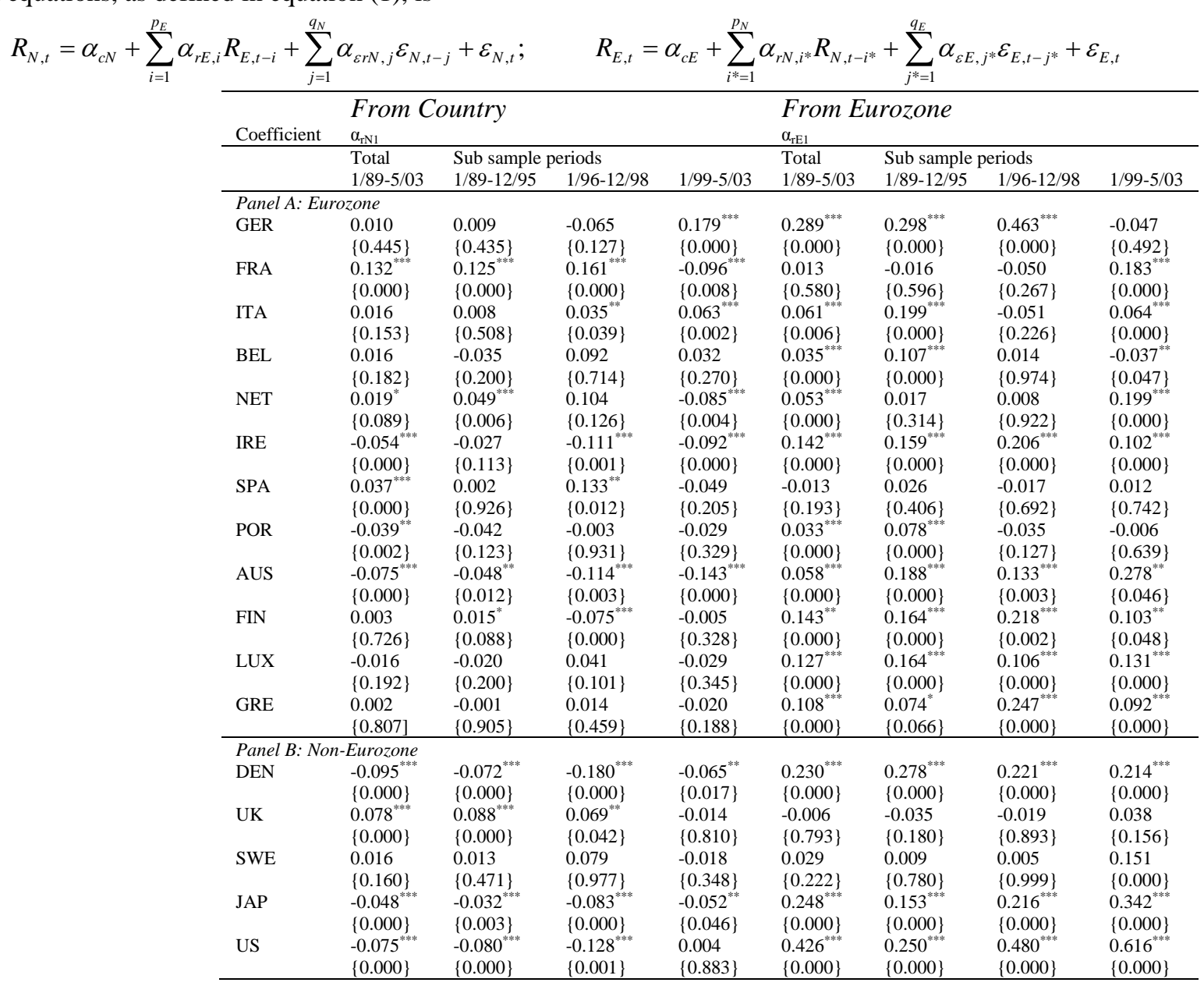




\section{Table 2}

\section{Bivariate ARMA-EGARCH-t results for stock market return volatility spillover}

This table presents the estimated spillovers in negative and positive shocks from national $\left(\beta_{\mathrm{N} 1}, \beta_{\mathrm{N} 2}\right)$ and regional ( $\left.\beta_{\mathrm{E} 1}, \beta_{\mathrm{E} 2}\right)$ stock market returns. Asymptotic $\mathrm{p}$-values are shown in the brackets. *,**,*** denote statistical significance at the 10,5 and $1 \%$ level respectively. The conditional volatility equations, defined in equations (2)-(3), are

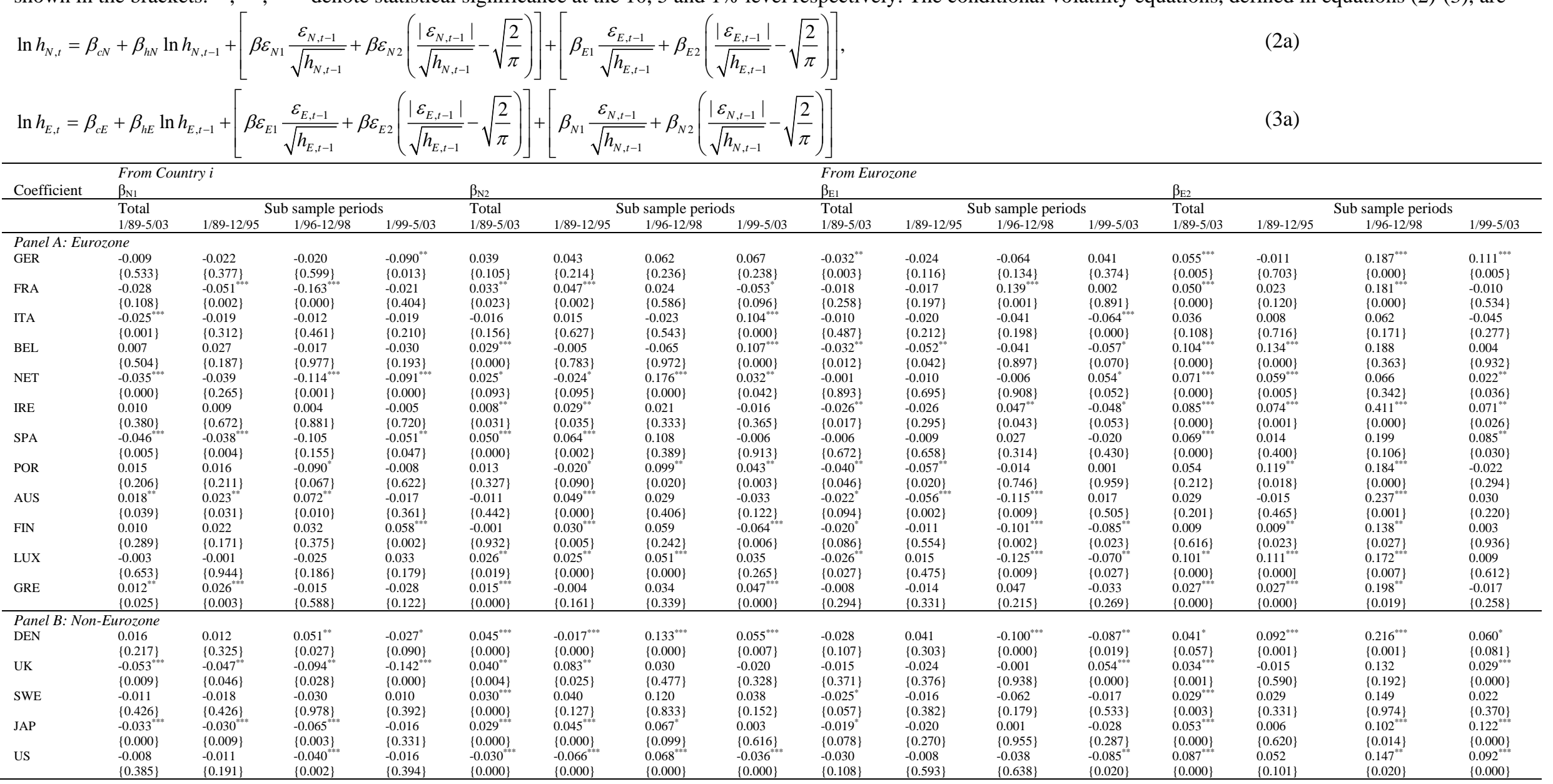




\section{Table 3}

\section{Determinants of Stock Market Integration}

In this table the seemingly unrelated regression (SUR) estimates are shown for the model defined in equation (7) $\hat{I N T_{i, t}}=\beta_{1 i}+\beta_{2 i} E X_{-} V O L_{i, t-1}+\beta_{3 i} O U T P U T_{i, t-1}+\beta_{4 i} I R A T E_{i, t-1}+\beta_{5 i} F I N_{-} D E P T H_{i, t-1}+\beta_{6 i} \log (V O L)_{i, t-1}+\beta_{7 i} F R I_{-} D U M_{i, t}+\beta_{8 i} J A N_{-} D U M_{i, t}+\beta_{9 i} I N \hat{T}_{i, t-1}+\beta_{10 i} I N T_{i, t-2}+u_{i t}$

where the dependent variable $\left(\hat{I N T}_{i, t}\right)$ is the estimated conditional correlation series for each country $i, E X \_V O L=$ exchange rate volatility, OUTPUT = correlations in the growth of industrial production rates with Euro area weighted averages, IRATE = correlations in nominal short term (30 day) interest rates with Euro area weighted averages, $F I N \_D E P T H=$ stock market capitalization/ GDP, $L O G(V O L)=$ logarithm of the stock market's turnover by volume, FRI_DUM and JAN_DUM are the seasonal dummies introduced before and $I N T_{i, t-1}^{\wedge}$ and $I N T_{i, t-2}$ are the first and second lags of the dependent variable. For Japan and the US, the result from an alternative specification with $I N F L A_{t-1}$ in place of IRATE $E_{t-1}$ is also reported.

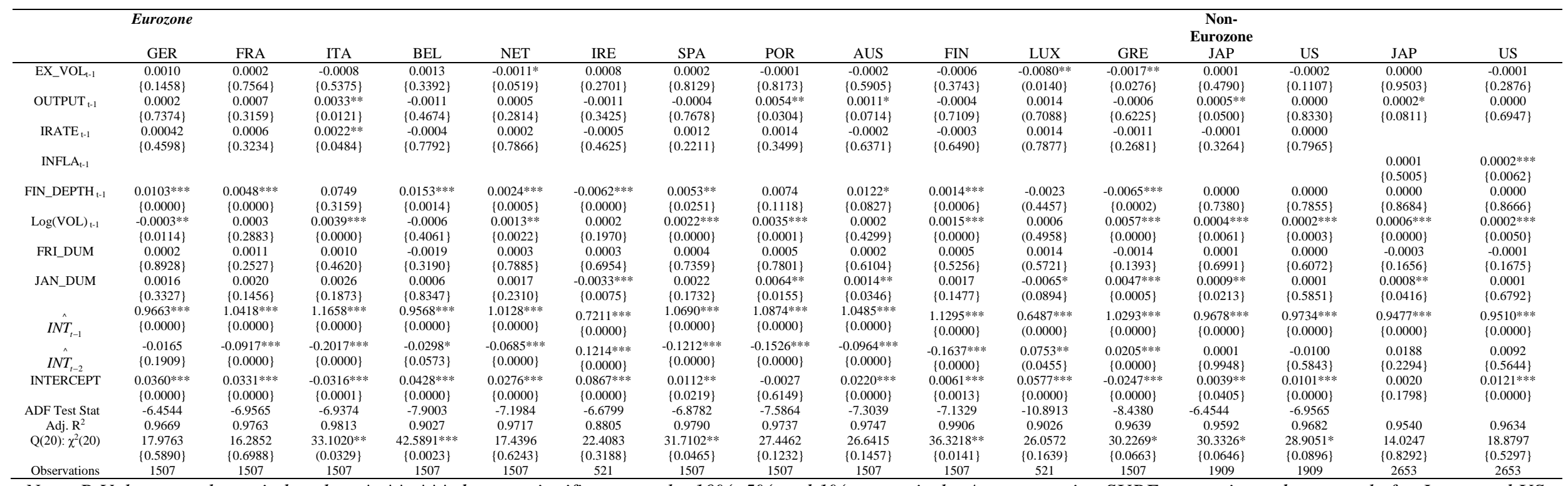

Note: P-Values are shown in brackets. *, **, *** denotes significance at the 10\%, 5\% and 1\% respectively. A two equation SURE was estimated separately for Japan and US and the correlation between the two residuals was 0.7243 and 0.7101 for including the IRATE $E_{t-1}$ and INFLA $A_{t-1}$ variable respectively. The SUR estimates shown for Ireland and Luxembourg are from a 12 equation SURE estimated using fewer observations, due to limited data availability. Critical Value for the Augmented Dickey Fuller (ADF) Test for a unit root at the 5\% significance level is -3.4100 . The appropriate ADF test included a constant, trend and 4 lags. 


\section{Table 4}

\section{Summary of significant variables in explaining stock market integration}

In this table, a summary of significant variables for explaining each country’s stock market integration with the EMU is presented. This summarises our findings from both unreported preliminary and reported regression analyses.

\begin{tabular}{|c|c|c|c|c|c|c|c|c|c|c|}
\hline & \multicolumn{5}{|c|}{ Economic Variables } & \multicolumn{2}{|c|}{ Financial Variables } & Seasonal Effects & \multicolumn{2}{|c|}{ Persistence } \\
\hline & EMU & EX_VOL & OUTPUT & IRATE & INFLA & FIN_DEPTH & LOG(VOL) & FRI_DUM JAN_DUM & $\hat{I N T}_{t-1}$ & $\hat{I N T}_{t-2}$ \\
\hline \multicolumn{11}{|c|}{ Panel A: Eurozone: } \\
\hline GER & $\mathrm{X}$ & & & & & $\mathrm{X}$ & $\mathrm{X}$ & & $\mathrm{X}$ & \\
\hline FRA & $\mathrm{X}$ & & & & & $\mathrm{X}$ & & & $\mathrm{X}$ & $\mathrm{X}$ \\
\hline ITA & $\mathrm{X}$ & & $\mathrm{X}$ & $\mathrm{X}$ & & & $\mathrm{X}$ & & $\mathrm{X}$ & $\mathrm{X}$ \\
\hline BEL & $X$ & & & & & $\mathrm{X}$ & & & $\mathrm{X}$ & $\mathrm{X}$ \\
\hline NET & $\mathrm{X}$ & $\mathrm{X}$ & & & & $\mathrm{X}$ & $\mathrm{X}$ & & $\mathrm{X}$ & $X$ \\
\hline IRE & & & & & & $\mathrm{X}$ & & $\mathrm{X}$ & $\mathrm{X}$ & $\mathrm{X}$ \\
\hline SPA & & & & & & $\mathrm{X}$ & $\mathrm{X}$ & & $\mathrm{X}$ & $\mathrm{X}$ \\
\hline POR & $\mathrm{X}$ & & $\mathrm{X}$ & & & & $\mathrm{X}$ & $\mathrm{X}$ & $\mathrm{X}$ & $\mathrm{X}$ \\
\hline AUS & $X$ & & $\mathrm{X}$ & & & $\mathrm{X}$ & & $\mathrm{X}$ & $\mathrm{X}$ & $\mathrm{X}$ \\
\hline FIN & & & & & & $\mathrm{X}$ & $\mathrm{X}$ & & $\mathrm{X}$ & $\mathrm{X}$ \\
\hline LUX & & $\mathrm{X}$ & & & & & & $\mathrm{X}$ & $\mathrm{X}$ & $\mathrm{X}$ \\
\hline GRE & & $\mathrm{X}$ & & & & $\mathrm{X}$ & $\mathrm{X}$ & $\mathrm{X}$ & $\mathrm{X}$ & $\mathrm{X}$ \\
\hline \multicolumn{11}{|c|}{ Panel B: Non-Eurozone: } \\
\hline JAP & $\mathrm{X}$ & & $\mathrm{X}$ & & & & $\mathrm{X}$ & $\mathrm{X}$ & $\mathrm{X}$ & \\
\hline US & & & & & $\mathrm{X}$ & & $\mathrm{X}$ & & $\mathrm{X}$ & \\
\hline
\end{tabular}

